\title{
Stage IV Renal Cell Cancer AJCC v6
}

National Cancer Institute

\section{Source}

National Cancer Institute. Stage IV Renal Cell Cancer AJCC v6. NCI Thesaurus. Code C4003.

Stage IV includes: (T4, N0, M0); (T4, N1, M0); (Any T, N2, M0); (Any T, Any N, M1). T4: Tumor invades beyond Gerota's fascia. N0: No regional lymph node metastases. N1: Metastasis in a single regional lymph node. N2: Metastasis in more than one regional lymph node. M0: No distant metastasis. M1: Distant metastasis. (AJCC 6th ed.) 